\title{
Búsqueda de hemoglobinas anormales en los recién nacidos en las grandes alturas.
}

ROA Dante*, AGUINAGA María del Pilar*, RUIZ Wilson**, ULLOA Víctor**, TURNER Ernest*.

*Comprehensive Sickle Cell Center, Meharry Medical College, Nashville, Tennessee, U.S.A.

** Universidad Peruana Cayetano Heredia, Lima Perú.

\section{SUMMARY}

Objective: Native newborns from three Andean cities located in Peru: namely Cerro de Pasco, Huancayo and Puno, with altitudes ranging from 10,000 to 14,000 feet above sea level, were screened for abnormal hemoglobins. Material and methods: With the participation of medical personnel in hospitals located in these cities, it was possible to screen a total of 234 newborn babies, Heel stick blood samples obtained were inmediately hemolyzed, refrigerated for few weeks and later analyzed by isoelectric focusing electrophoresis and high performance liquid chromatography (Waters and BioRad) screening procedures. Results: This results indicated that the newborn babies tested had normal hemoglobin profiles. Conclusion: No abnormal hemoglobin variants were detected in these samples at the initial screening. (Rev Med Hered 1997; 8:87-91).

KEY WORDS: Newborn screening, hemoglobinophaties, high altitude.

\section{RESUMEN}

Se hizo un muestreo para detectar hemoglobinas anormales en Recién Nacidos (RN) de tres ciudades andinas situadas en el Perú: Cerro de Pasco, Huancayo y Puno. Estas ciudades estan situadas en altitudes que fluctúan entre los 3,500 a 4,400 m. sobre el nivel del mar. Objetivo: Investigar la presencia, de hemoglobinas anormales en RN nativos de altura. Material y Métodos: Participaron un total de 234 RN. Se obtuvieron muestras de sangre del talón que fueron inmediatamente hemolizadas y refrigeradas para luego ser analizadas mediante electroforesis de punto isoeléctrico y cromatografía líquida de alto rendimiento. Resultados: Los resultados indicaron que los RN tenían perfil de hemoglobina normal (Hb A/F). Conclusiones: En estas muestras, que corresponden a una evaluación piloto, no se detectó ninguna variante anormal de hemoglobina, ni hemoglobinas de migración rápida (Hb H, Hb Bart's). (Rev Med Hered 1997; 8:87-91). 
PALABRAS CLAVE: Hemoglobinas, recién nacidos, grandes alturas, hemoglobinopatías

\section{INTRODUCCION}

Antecedentes históricos:

A la llegada de los conquistadores, la población andina se estima que era superior a los veinte millones de habitantes. En la actualidad, en América existen aún zonas con un fuerte componente poblacional indígena como ocurre en Méjico, en América Central y en América del Sur: Perú, Bolivia y Ecuador. Desde la colonización, iniciada hace 500 años, han llegado a este continente: africanos, asiáticos y europeos para formar parte de lo que hoy en día es la sociedad Latinoamericana.

Además de la contribución cultural, étnica y social que aportaron estos inmigrantes; también trajeron consigo rasgos genéticos y fisiológicos propios, que ahora están siendo reconocidos como causantes de algunas enfermedades prevalentes en ciertas comunidades latinoamericanas. Un ejemplo de esto lo constituye el primer caso de anemia drepanocítica, que fué descrita en un nativo de las Antillas Británicas en los inicios de 1900 por el Dr. J.B. Herrick.

Posteriormente y gracias al desarrollo de procedimientos de laboratorio más eficientes y rápidos, la detección de hemoglobinas anormales en grandes grupos poblacionales se ha hecho factible, al punto que en los Estados Unidos es obligatorio. Pero en Latinoamerica y en el Perú específicamente la detección e identificación de hemoglobinas se realiza en forma esporádica y en algunos casos es inexistente.

Un muestreo realizado para determinar la frecuencia de $\mathrm{HbS}, \mathrm{HbC}, \mathrm{HbD}, \mathrm{HbA2}$, beta Talasemia y G-6-PDH en diferentes grupos raciales de Latinoamérica y del Caribe, han señalado que la HbS está completamente ausente en los grupos caucásicos y en aborígenes americanos, pero si se han hallado, HbS y el rasgo de HbS, en los descendiente africanos y en grupos mestizos con ancestros africanos.

Estudios en las grandes alturas:

La literatura científica sobre $\mathrm{Hb}$ y hemoglobinopatías en los individuos que viven por encima de los 3,000 m.s.n.m. es escasa. La información principalmente, se relaciona con la respuesta fisiológica y bioquímica de los eritrocitos (1), como: incremento en los niveles de metahemoglobina debido a la hipoxia de altura (2)(3), moderada policitemia, hiperhemoglobinemia, microcitosis, e hiperactividad metabólica con acumulación de 2,3DPG y ATP (4).

Los pocos estudios comparativos de $\mathrm{RN}$ y adultos aparentemente normales, que viven por encima de 3,000 m.s.n.m. no detectaron hemoglobinas anormales (5) 
La investigación de la existencia de $\mathrm{Hb}$ anormales es importante ya que nos permitirá prevenir mayores problemas de salud, tal como se hace con los portadores de hemoglobinas drepanocíticas.

Pocos estudios publicados han permitido la identificación de un caso de mutación de cadena alfa de hemoglobina en un hombre de 22 años y su progenitora de 45 años, nativos del altiplano boliviano (6) y una segunda hemoglobina con cadena beta mutante " $\mathrm{Hb}$ Illimani” identificada en una mujer boliviana de 66 años, pero cuyos ancestros no eran nativos de altura (7).

Salvo estos trabajos, no hemos encontrado informes en los que se haya investigado de manera sistemática la existencia de hemoglobinopatías en individuos que viven a grandes alturas.

Considerando que un tercio de la población peruana vive en los Andes, la investigación del perfil de hemoglobina de estos individuos es pertinente ya que nos ayudará a conocer la existencia o no, de un factor genético que podría tener importancia respecto a la adaptación o la patología de los que viven en estas zonas geográficas.

El objetivo del presente trabajo fue investigar la presencia, o no, de hemoglobinas anormales en individuos nativos de las ciudades de: Huancayo, Puno y Cerro de Pasco y si las hubiere, ofrecer asesoría médica y el consejo genético respectivo a sus familiares.

\section{MATERIAL Y METODOS}

\section{Selección de voluntarios:}

Previa obtención del Consentimiento Informado se procedió a colectar 234 muestras de sangre de RN y 200 muestras de mujeres adultas que acudieron, en trabajo de parto, a hospitales y centros de salud en las localidades de: Huancayo (3,500m), Puno $(3,800 \mathrm{~m})$ y Cerro de Pasco (4,400m). La totalidad de los participantes fueron campesinos o pequeños comerciantes de las zonas rurales, salvo algunos citadinos de la ciudad de Huancayo. La totalidad de los voluntarios fueron hijos y nietos de habitantes de la zona andina.

\section{Toma de muestras de sangre:}

Se tomaron muestras de sangre capilar, del talón en los RN y del pulpejo del dedo en los adultos, utilizando una lanceta estéril. Fueron colectadas en papel de filtro Whatman de $5 \mathrm{x}$ $5 \mathrm{~mm}$, que almacena aproximadamente $10 \mu \mathrm{l}$ de sangre.

Se utilizó un mililitro de solución hemolizante de Helena colocado en un tubo eppendorff de $1.5 \mathrm{ml}$ de volumen, dentro del cual se introducían las tiras de papel con la muestra en número suficiente como para teñir de rojo el líquido (de 1 a 3). Los tubos así preparados fueron sellados, etiquetados y almacenados a $4{ }^{\circ} \mathrm{C}$ para preservar las muestras hasta por un tiempo de 6 meses. 


\section{Análisis de las muestras de sangre:}

Esto se hizo por tres diferentes métodos: Electroforesis de punto-isoeléctrico(IEF); cromatografía líquida de alto rendimiento (HPLC), utilizando la variante Bio-Rad (HPLC Bio-Rad) y por último HPLC utilizando 600 E multi solvente de Waters.

\section{Electroforesis de punto-isoeléctrico (IEF)}

Es una técnica de separación electroforética de la Hb (Isolab, Inc. Drawer 43, Akron, Ohio 44321, USA) que consiste fundamentalmente en aplicar una muestra de sangre hemolizada a un gel de agarosa, previamente elaborado con sustancias anfolíticas de bajo peso molecular y con puntos isoeléctricos diferentes. Cuando una corriente continua se aplica al sistema las moléculas anfotéricas migran hacia sus puntos isoeléctricos (pI) creando una gradiente de $\mathrm{pH}$ estable. En estas condiciones se colocan $5 \mathrm{ml}$ del hemolizado, los cuales migran atraves del gel hasta alcanzar el lugar donde su pI iguala el pH del gel, en este lugar su carga eléctrica neta es cero y la migración cesa. De esta manera y usando controles conocidos, se pueden identificar las diferentes $\mathrm{Hb}$ y cuantificarlas, mediante un sistema especial de tinción.

\section{Cromatografía líquida de alto rendimiento (HPLC) (Versión Bio-Rad).}

Se trata de un sistema de HPLC completamente automatizado específicamente diseñado para el estudio de Hbs. Las muestras de hemolizado son colocadas en un buffer, el cual mediante un sistema de bombeo de doble pistón hace llegar la mezcla a los sensores analíticos en donde la muestra es separada en sus componentes individuales, y son medidos por espectrofotometría mediante un sistema de doble longitud de onda (415 y $690 \mathrm{~nm}$ ). Toda la información de absorbancias son procesadas por una computadora usando un programa analítico específico para hemoglobinas (Group, 4000 Alfred Nobel Drive, Hércules, California 94547).

Sistema de HPLC usando: Waters 600 E multisolvent (Waters Chromatography Division, 397 Williams Street, Marlborough, Massachusetts 01752-9162).

Las muestras de hemolizado son centrifugadas a $12000 \mathrm{rpm}$ y a $4{ }^{\circ} \mathrm{C}$ por 15 minutos y luego filtradas a través de poros de 0.25 a $0.45 \mu$ de diámetro. Alicuotas de $10 \mathrm{ml}$ fueron transferidas a viales estilo-H Nalgene.

Se usaron columnas metálicas Polycat 300 con polímeros catiónicos hidrofílicos. Se creó una gradiente con fase mobil A conteniendo: buffer Bis Tris $40 \mathrm{mM}, 4 \mathrm{mM}$ de KCN a pH 6.5 y una fase mobil B compuesta por buffer Bis-Tris $40 \mathrm{mM}, 4 \mathrm{mM}$ de KCN, CINa 0.2 $\mathrm{M}$ a $\mathrm{pH}$ 6.8; corriendo a un flujo de $2.0 \mathrm{ml} / \mathrm{min}$ durante 30 minutos. Las lecturas se hicieron en rango ultravioleta de $436 \mathrm{~nm}(8)$.

\section{RESULTADOS}

Al analizar las 234 muestras sanguíneas de RN encontramos un patrón normal de 
hemoglobinas. No se detectaron hemoglobinas anormales, síndromes falciformes o hemoglobinas de migración rápida.

En la tabla $\mathrm{N}^{\circ} 1$ se presentan los valores porcentuales comparativos, obtenidos para la $\mathrm{Hb} \mathrm{F}$ y la $\mathrm{Hg} \mathrm{A}$, en las 234 muestras analizadas con los sistemas cromatograficos de Bio-Rad y Waters.

\section{DISCUSION}

Como ya reportamos previamente, el método de colectar muestras de sangre en papel de filtro, es útil para preparar hemolizados que permiten estudiar las hemoglobinas mediante técnicas tradicionales y/o modernas (8); incluso luego de haberlas almacenado hasta 12 semanas a temperatura ambiente. Esto nos ha permitido colectar un buen número de muestras de zonas en donde no siempre existen facilidades para este tipo de trabajo. Para un país como el Perú, que se caracteriza por su diversidad geográfica, esta metodología de trabajo es de gran ayuda.

Estudios comparativos de perfiles de $\mathrm{Hb}$ en personas adultas normales que viven a 4,515 msnm, y 20 individuos normales que viven a 1,270 msnm, no mostraron diferencias, a pesar de la eritrocitosis presente en los que viven a mayores alturas (9).

Algunos estudios hematológicos de $\mathrm{RN}$ a diferentes niveles de altura en el Perú (Lima 150m, La Oroya 3,700, Cerro de Pasco 4,450 y Morococha 4,500 m.) mostraron promedios muy parecidos para: $\mathrm{Hb}$, reticulocitos, volumen sanguíneo, volumen plasmático, volumen de los hematíes, vida media de eritrocitos y hierro sérico (10).

Se ha sugerido que el incremento en la masa de hematíes puede NO ser un mecanismo adecuado de compensación a la hipoxia de las grandes alturas, debido a que puede llegar a ocasionar una falla en las propiedades reológicas circulatorias de la sangre (11). Estudios cuantitativos y cualitativos de la $\mathrm{Hb}$ en los pacientes que sufren eritrocitosis patológicas de las grandes alturas no encontraron mutaciones de la $\mathrm{Hb}(8,12)$.

Hay reportes controvertidos en relación al efecto de la altura en los pacientes que tienen rasgos falciformes pues algunos sufren de infartos esplénicos o muerte súbita (13). Sin embargo los participantes africanos con rasgo falciforme, que compitieron en los Juegos Olímpicos de México (2,100msnm), no presentaron ninguna sintomatología clínica. Igualmente hay reportes que refuerzan el hecho de que sujetos portadores de $\mathrm{Hb} \mathrm{S}$ que viajan a grandes alturas (aproximadamente 3,300 msnm) han desarrollado severa hipertensión e infarto de bazo $(14,15)$

Siendo el objetivo del presente estudio la búsqueda de $\mathrm{Hb}$ anormales, específicamente la Hb S y su posible relación con el hábitat de altura, podemos afirmar que en las poblaciones investigadas NO hemos detectado ningún caso de hemoglobinopatía.

Una observación interesante, hecha a partir de los datos obtenidos, es que al parecer conforme avanzamos en altitud el porcentaje de $\mathrm{Hb} \mathrm{F}$ va disminuyendo mientras que la $\mathrm{Hb}$ 
A va aumentando. Debido a que el diseño del presente trabajo no nos permite sacar conclusiones al respecto, esperamos en un futuro cercano poder realizar un estudio especialmente dirigido a esclarecer estos interesantes hallazgos.

\section{REFERENCIAS BIBLIOGRÁFICAS}

1.Arnaud J, Gutiérrez N, Vergnes H. Función respiratoria del glóbulo rojo en la altura. Anuario 1979 del Instituto Boliviano de Biología de Altura, 1980: pp 46 - 52

2.Arnaud J, Gutiérrez N, Quilice JC, Vergnes H. Metahemoglobinemia de altura. Metahemoglobina y NADH diaforasas. Anuario 1983-1984 del Instituto Boliviano de Biología de Altura 1984: pp 141-144.

3.Ballew , Haas JD. Hematologic evidence of fetal hipoxia among newborn infants at high altitude in Bolivia. Am J Obstet Gynecol 1986; 155(1): 166-169.

4.Arnaud J, Gutiérrez N, Tellez W, Vergnes H. Hematology and erythrocyte metabolism in man at high altitude: an Aymara -Quecchua comparision. Am J Phys Anthropol 1985; 67(3):279-288.

5.Aste-Salazar H, Krundieck CL. Diferenciación de hemoglobinas humanas en las grandes alturas. I. Hemoglobina fetal en recién nacidos y en adultos. Ginecol \& Obstet 197l;17(l2):79-102.

6.Galarza GM. Vargas E, Spielvogel H, Peñaloza R, Contreras G, Rodriguez AS, Gutiérrez N. Comunicación del primer hallazgo de la hemoglobina mutada en Bolivia :Hb J Bolivia”. Anuario 1989-1990 del Instituto Boliviano de biología de la Altura, 1991: pp 111-118.

7.Galarza GM, Rodrigo G, Aguilar M, Escalante A, Averanga J. Comunicación de la segunda hemoglobina mutada en Bolivia "Hb Illimani". Cuad Hosp Clin 1991; 37(1): 2833.

8.Roa PD, Turner E, Aguinaga MdP. Hemoglobin variant detection from dried blood specimens by high performance liquid chromatography. Ann Clin Lab Sci 1993;23:433438.

9.Galarza GM, Vargas E, Villena M. Hemoglobinas en eritrocitosis de habitantes de la altura. Anuario 1986-1987 del instituto Bolivariano de biologia de la altura, 1987:pp 99104.

10.Mairbaurl H. Red blood cell function in hipoxia at altitude and exercise. Institute of Sport Medicine, University of Heilderberg, Germany. Int J Sports Med 1994; 15(2): 5163.

11.Gonzales GF, Guerra-García R. Niveles de hemoglobina en residentes de Cerro de Pasco (4200m): según procedencia, actividad y edad. Acta de las primeras Jornadas de Medicina y Cirugía de altura. La Oroya, Centromin Perú, 1978: pp 166-171.

12.Rathe G. Estudio de la hemoglobina de residentes-a $4515 \mathrm{~m}$ sobre el nivel del mar. XXI Congreso Internacional de Ciencias Fisiológicas: Resumen de las comunicaciones /XXI International Congress of Physiological Sciences: abstracts of comunications. Buenos Aires 1959, p 226.

13. Konotey-Ahulu F.I.D. Sickle cell trait and altitude. Bri Medi 1, 1972:p 177.

14. Kopp P, Negri M, Wegmuller E, Cottier P. Schweiz Med Wochenschr. Sep 30, 1989;119(39): 1358-9.

15.Narasimham C, George T, George JT, Pulimood BM. Hypertension in sickle cell 
disease. J Assoc Physicians 1990; 38(6): 435-436.

Este trabajo fue financiado por NIH-Fogarty Internacional Center Grant \# 1TW00043 y NIH Grant P60-HL38737

\section{Agradecimientos:}

Los autores extienden su reconocimiento y aprecio a todos los profesionales de la salud que hicieron posible la colección de muestras de sangre de los individuos que viven en las localidades de las grandes alturas. En particular nuestra gratitud se hace extensiva a los Drs. Cesar A. Reyes y Víctor Buendía Sotelo del Hospital Daniel A. Carrión en Huancayo, a la Dra. Nancy López C. Del Hospital D.A. Carrión de Cerro de Pasco y al Dr. Elías Aycacha M. en Puno. También al Dr. Alberto Diaz A. y a la Srta. Susy Araníbar S. de la Universidad Peruana Cayetano Heredia Lima, quienes dispusieron de su tiempo y experiencia en coordinar las actividades que lograron la colección de muestras de sangre en estas tres diferentes localidades del Perú

\section{Correspondencia:}

Dr. Wilson Ruiz Gil

Laboratorio de Hematología. Instituto de Investigaciones de la Altura. Universidad Peruana Cayetano Heredia. Av. Honorio Delgado s/n. San Martín de Porres, Lima, Perú 